\title{
Pasalitang Filipino ng mga mag-aaral sa Sorsogon State College
}

\author{
Marbella, Felisa D. $\$ \\ Sorsogon State College, Sorsogon City, Philippines (felymarbella03@gmail.com)
}

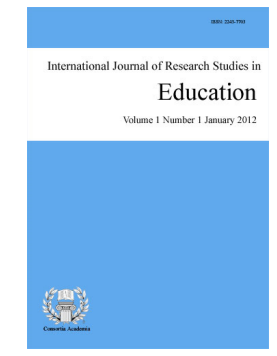

ISSN: $2243-7703$

Accepted: 22 June 2020 Online ISSN: 2243-7711

OPEN ACCESS

\section{Abstract}

This research aims to determine the communication skills in speaking Filipino language of college students. Analytical-descriptive tests were used to determine the communication skill of 200 students from four (4) campuses of Sorsogon State College department. Purposive sampling was used to identify the participants in this study. The auxiliary equipment was tape recorder, cellphone and checklist were used to collect data. The data were analyzed using frequency count and percentage. The result of the study shows that the type of communication skill in speaking Filipino is not standard Filipino but that Filipino with English. The pronunciation of the students in the segmental phonemes /e/ - /i/ and /o/ - /u/ is not arbitrary. Paraphrasing is the type of lexicon used by the students. The use of short and long sentences using syntax in speaking Filipino is moderate. There is a partial codeswitching used. It is recommended that the teachers give more oral practicum to students who are less proficient in the Filipino Language towards greater fluency in their own language. All Filipino teachers will be given the opportunity to attend Filipino workshops to further develop their ability to speak Filipino. Conduct other studies on spoken Filipino in different parts of the Philippines that will be the basis of the Filipino standardization process.

Keywords: speaking Filipino; lexicon; phonology; syntax 


\section{Pasalitang Filipino ng mga mag-aaral sa Sorsogon State College}

\section{Introduksiyon}

Ang wika ay dumaraan sa proseso ng pagbabago. Sa katunayan, napakadalas ng pagbabagu-bago ng wika. Ang isang wika ay maaaring magpasok ng ilang pagbabago o di kaya ay tahasang magbago ang anyo upang matugunan ang pangangailangan ng mga taong gumagamit nito. Ang wika ay patuloy sa pagbabago habang patuloy ang gumagamit nito. Ang anumang pagbabago ay nakakaapekto sa iba. Kapag hindi naman nagagamit nang tama o husto ay maaari itong mamatay nang tuluyan. Sa ngayon, maraming uri ng Filipino ang ating nariring. Natural lamang ang gayon sa isang wikang napakabilis ng pag-unlad. Sa dakong huli alam nating magtatagpu-tagpo pa rin ang iba't ibang uring ito upang bumuo ng matatawag na wikang Filipino (Santiago at Tiangco, 2003).

Ang pagkakaroon ng sariling wika ay masasabing katumbas ng pagkakaroon ng sariling mga paa dahil ito ang tumatayong instrumento upang tayo'y magkaunawaan at magkaisa kung saan ito ang unang hakbang sa kaunlaran. Ang sariling wika ang siyang mga paa na tumatayo sa bawat Pilipino upang humakbang at magsimulang makipag-ugnayan na siyang magdadala ng bansa sa kaunlaran (Boydon, 2014). Ayon nga kay Yule (2014) ang wika at pamamaraan ng paggamit nito ay isang porma ng panlipunang identidad at ginagamit, malay man o hindi, upang ipahiwatig o maging palatandaan ng pagiging kasapi ng isang tao sa isang tiyak na grupong panlipunan. Kung gayon, mahalaga ang pamilyarisasyon ng isang gumagamit ng Filipino sa mga proseso ng pagbubuo ng mga salitang Filipino, sapagkat magiging mga pleksibol siya sa paggamit sa wikang ito kung malay siya sa mga ito (Bernales, 2016).

Samakatuwid, ang bawat pagsasalita ng isang indibidwal sa bawat indibidwal anumang wika ang gamitin ay may kaakibat na layunin. Ang layunin ito ay magbubunsod sa kanya na ipaabot ang kanyang nais sa buhay. Sa pagsasalita naipapahayag nang isang tao ang anumang iniisip, nararamdaman, nakikita o anumang bagay na nais ipahayag. Sa bawat pagsasalita ay may kaangkinang mensahe itong napapaabot. Nakadepende sa taon kung paano niya ito mauunawaaan. Samakatuwid, nagkakaroon ng iba't ibang kahulugan ang isang salita batay na rin sa motibo ng tagapaghatid ng mensahe. Nasa nagsasalita na rin kung gaano kalawak ang kaniyang kaalaman sa wikang kanyang ginagamt. Nakabatay rin sa leksikon ng wika ang maaaring maabot ng isang kahulugan.

Ang bisyon ng Komisyon sa Wikang Filipino ang magawa ang Filipino na isang modernong wika na magagamit na mabisang kasangkapan sa kabuuan ng pambansang pagpapaunlad (Almario, 2015). Ibig sabihin lamang nito na patuloy na papalaganapin ang pambansang wika upang magamit ito sa pang-araw-araw na pakikipagtalastasan at maging sa mga transaksyon na siyang maghahatid ng kaunlaran sa bansa. Ang bisyon na ito ng KWF ay tumutugon lamang sa itinatadhana ng Konstitusyon ng 1987, Atas Tagaganap Blg.335 na nagsasabing: Ang wikang pambansa ng Pilipinas ay Filipino na samantalang nalilinang ito ay dapat payabungin at pagyamanin pa salig sa umiiral na mga wika ng Pilipinas at sa iba pang wika at ukol sa mga layunin ng komunikasyon at pagtuturo. Dahil sa pangunahing hangaring ito, inilunsad ng Departamento ng Edukasyon at Commision on Higher Education ang paglilinang at pagpapayabong ng Filipino bilang wika ng pangkarunungang pagpapahayag na nangangahulugang patuloy na intelektwalisayon nito.

Bilang pag-alinsunod sa mga nasabing batas, ang Filipino ay kailangang higit pang linangin at pagyabungin upang ito ay magsilbing kasangkapan sa pag-unlad ng bansa at maging instrumento sa mabisa at malinaw na pakikipagtalastasan. Samakatuwid, hindi lamang ang wikang Filipino ang kailangang paunlarin. Dapat ding paunlarin ang kasanayan sa paggamit nito maging sa pagpapahayag na pasalita o pasulat. Sa naging resulta ng isinagawang pag-aaral ni Ojos (2020) natukoy nito na maraming salik ang nakakaapekto sa kakayahan ng mga mag-aaral sa pagsulat ng pananaliksik batay sa nilalaman, pagkakabuo, at mekaniks. Nalaman nito na

10 Consortia Academia Publishing (A partner of Network of Professional Researchers and Educators) 
nahihirapan ng mga mag-aaral sa pagpapahayag ng kanilang iniisip sa pagpapahayag na pasulat. Kung kaya't inirerekomenda nito na magbigay o magsagawa ng mas maraming gawaing pagsasanay ang mga mag-aaral upang malinang ang kanilang pagkatuto sa nilalaman, pagkakabuo, at mekaniks sa pagsulat upang maging daan din na mahubog ang kanilang kakayahan sa pagsasalita. Kinakailangan itong gawin sapagkat maraming sagabal na may malaking ambag sa mabagal na pag-unlad ng Wikang Filipino.

Hindi natin maikakaila na ang mga nagsusulputang teknolohiya, patuloy na pagtangkilik sa wikang banyaga, at maling paniniwala na napakadali ng Filipino na pag-aaralan at matutuhan ay ilan sa mga dahilan kung bakit mahina ang mga mag-aaral sa paggamit ng wikang Filipino sa pakikipagtalastasan. Mapapansin na karamihan ngayon lalo na sa telebisyon at radyo, maririnig lagi ang paggamit ng pinaghalo-halong wika sa pagsasalita. Bihira na lamang ang nagsasalita gamit ang standard na Filipino, bilang na lamang sila sa mga daliri. Ang iba pa nga mas gustong gamitin ang Ingles kaysa sa Filipino dahil sinasabi nila na mas komportable sila sa paggamit ng Ingles. Pinatunayan ito sa naging resulta ng pag-aaral ni Jamisola (2020) na sinasabing iba't ibang uri ng pagpapalit koda ang ginagamit sa mass media sa pagbuo ng mga balita sa pahayagan, telebisyon, at radyo at ang lahat ng mga ito ay madala ginagamitan ng pagpapalit koda. Dahil ditto may malaking kaugnayan ang nagagawa ng pagpapalit koda sa mass media sa pag-unlad ng Wikang Filipino na nagkakaroon ng suliraning kinakahrap. Ang iba naman ay gumagaya na lang lalo na sa mga kabataan. Kapag narinig ang kakaiba, ang atensyon at interes nila dito ay lumalaki na dahilan upang gustuhin o gamitin nila. Ngunit ang katotohanan nito ay hindi nila alam na nasisira ang wika, at ang mas malala ay kung tuluyan na itong mamatay dahil hindi na ginagamit. Ayon nga sa pag-aaral ni Jolo (2020) dahil sa paggamit ng millenial slang naging epekto nito ang pagiging di maayos ng istruktura sa pagbuo ng pangungusap o pahayag. Malaki pa rin ang papel na ginagampanan ng mga social networking sites sa pagsulat ng mga mag-aaral sapagkat matuturingan na ang mga interaktibong midyang ito ay tanghalan ng iba't ibang pamamaraan at proseso ng impormal na komunikasyon kung saan nagiging lantad, babad, at sanay ang mga mag-aaral. Dahil dito masasalamin naman ang di magandang epekto ng mga kasanayang ito maging sa kanilang pagsusulat.

Ang pag-aaral ng wika ay naglalayong magkaroon ng kasanayan sa paggamit nito. Kailangang umabot sa pamantayang maging malinaw at mabisang maipahayag ang mensahe sa pagbubuo, pagsasaayos, at pagbibigkas ng mga panungusap. Ang kalinawan sa pagpapahayag ay nasasalig sa mga diwang ipinapahayag, maaaring ang kasanayan sa pagbuo ng mabisang mga pangungusap gayundin sa pagpili ng mga tumpak at akmang mga salita at paggamit ng paraan ng pagbigkas. Ang kalinawan samakatuwid ay masasabing pangunahin sa alinmang pagpapahayag lalo na sa pagsasalita. Subalit sa mga mag-aaral ng Sorsogon State College ay hindi gaanong mapapansin kung ito ay nasusunod sa pamantayan. Hindi maririnig sa kanilang pagsasalita ang kalinawan lalo na sa mga mag-aaral sa kolehiyo. Kaugnay nito, kung kaya't kailangang malaman ang uri ng pasalitang Filipino ng mga mag-aaral sa pakikipagtalastasan sa paaralan (Delima, 1996).

Kaya naman, napapanahon na pagtuunan ng pansin ang antas ng kakayahan sa paggamit ng wikang Filipino ng mga mag-aaral lalo na sa pagsasalita upang sa gayon maging buhay ang pagpapayaman ng ating pambansang wika dahilan upang ang pag-aaral na ito ay mabuo. Sa adhikain ito, ninais na alamin ang antas sa pasalitang Filipino upang maging daan na makabuo ng mga paraan na umunlad pang lalo. Dagdag pa nito naging obserbasyon ng mananaliksik ang kawalan ng maayos na pasalitang komunikasyon ang mga mag-aaral. Hirap silang makipag-usap gamit ang wikang Filipino. Hindi nila lubusang naipapahayag ang nais sabihin gamit ang sariling wika. Ito ang nag-udyok sa mananaliksik na gawin ang nabanggit na pag-aaral.

\subsection{Paglalahad ng Suliranin}

Layunin ng pag-aaral na ito na masuri ang pasalitang Filipino ng mga mag-aaral sa antas kolehiyo sa Sorsogon State College. (1) Matukoy ang uri ng pasalitang Filipino ng mga mag-aaral. (2) Malaman ang uri ng ponolohiya ng pasalitang Filipino ng mga mag-aaral. (3) Matukoy ang uri at sintaks na kanilang ginagamit sa pasalitang Filipino. 


\section{Pamamaraang ginamit}

Ang pananaliksik na ito ay gumamit ng analitikal-palarawang pagsusuri na naglalayong malaman ang pasalitang Filipino ng mga mag-aaral. Ang disenyo ng pag-aaral na ito ay cross sectional. Ang mga respondent sa pag-aaral na ito ay binubuo ng 100 na mag -aaral mula sa apat (4) na departamento. Tiglilimampung (50) respondent mula sa departamento ng edukasyon, teknolohiya, accountancy, at inhenyero at arkitektura. Purposive sampling ang ginamit sa pagpili ng mga respondent. Ang pag-aaral na ito ay natamo sa paggamit ng patnubay sa pakikipanayam at tseklist. Inihanda ang tseklit upang matamo ang uri ng pasalitang Filipino ng mga mag-aaral ay inuri kung ito ay standard, Filipino na may Ingles, at Filipino na may Ingles at Bikol. Sa katangian ng ponolohiya, sinuri ang alternasyon ng ponemang segmental na /e/ - /i/ at /o/ - /u/ sa mga ginamit na salita ng mga respondent na itineyp sa pakikipanayam. Ang leksikon ay binatay sa kung ito ay panghihiram, pag-iimbento ng mga bagong salita, paraphrasing at inkorporasyon. Ang sintaks, ang haba ay sinuri ayon sa katamtamang paggamit ng maikli at mahabang pangungusap, maramihang paggamit ng mahabang pangungusap, katamtamang paggamit ng pangungusap na may isa hanggang apat na sugnay, maramihang paggamit ng pangungusap na may dalawa hanggang tatlong sugnay, at madalang na paggamit ng pangungusap na may lima o mas maraming sugnay at sa codeswitching naman kung ito ay partial o lubusan (Santiago at Tiangco, 2003). Inihanda rin ang patnubay sa pakikipanayam. Ang patnubay sa pakikipanayam ay tungkol sa: palabas o pelikulang napanood na nandoon ang paboritong artista, palabas sa telebisyon na palaging pinapanood, at mensaheng nakapaloob ditto. Ito ang pinagbatayan upang matamo ang pasalitang Filipino ng mga mag-aaral. Pantulong na kagamitan ang tape recorder at cellphone na ginamit sa pagteyp ng mga kasagutan ng mga mag-aaral sa katanungan ng mananaliksik. Ang mga nalikom na datos ay sinuri at inalisa gamit ang frequency count at bahagdan.

\section{Mga natuklasan}

Inilahad dito ang pagsusuri at interpretasyon ng mga datos na nakuha ukol sa pasalitang Filipino ng mga mag-aaral sa kolehiyo. Ang mga nakalap na datos ay inilagay sa talahanayan para sa ikalilinaw at ikakadali ng pagsusuri ng pasalitang Filipino, uri ng ponolohiya, leksikon, at sintaks ng mga mag-aaral.

\subsection{Uri ng pasalitang Filipino ng mga mag-aaral sa antas kolehiyo}

Ang pasalitang Filipino ay tumutukoy sa pag-aaral ng uri ng Filipino, uri ng ponolohiya, leksikon, at sintaks ng mga mag-aaral. Makikita sa Talahanayan 1 ang mga respondent sa pag-aaral na natamo sa pamamagitan ng random sampling na may kabuuang bilang na dalawang daang (200) mag-aaral. Limampung (50) mag-aaral ang kumakatawan sa bawat departamento na kalahok sa pag-aaral.

\section{Talahanayan 1}

Uri ng pasalitang Filipino ng mga mag-aaral

\begin{tabular}{|c|c|c|c|c|c|c|c|}
\hline Kolehiyo & $\begin{array}{l}\text { Standard } \\
\text { Filipino }\end{array}$ & $\%$ & $\begin{array}{l}\text { Filipino na } \\
\text { may Ingles }\end{array}$ & $\%$ & $\begin{array}{c}\text { Filipino na } \\
\text { may Ingles } \\
\text { at Bikol }\end{array}$ & $\%$ & $\begin{array}{c}\text { Kabuuang } \\
\text { bilang ng mga } \\
\text { mag-aaral }\end{array}$ \\
\hline Edukasyon & 20 & 40 & 18 & 36 & 12 & 24 & 50 \\
\hline Teknolohiya & 10 & 20 & 25 & 50 & 15 & 30 & 50 \\
\hline Enhinyero at Arkitektura & 17 & 34 & 24 & 48 & 9 & 18 & 50 \\
\hline Accountancy & 16 & 32 & 25 & 50 & 9 & 18 & 50 \\
\hline Kabuuan & 63 & 31.5 & 92 & 46 & 45 & 22.5 & 200 \\
\hline Ranggo & & 2 & & 1 & & 3 & \\
\hline
\end{tabular}

Ipinapakita na ang uri ng pasalitang Filipino ng mga mag-aaral sa antas kolehiyo ng SSC na kinakatawan ng apat (4) na departamento ay nakararami 92 o 46 bahagdan ang Filipino na may Ingles, 63 o 31.5 na bahagdan ang standard na Filipino, samantalang 45 o 22.5 na bahagdan ang Filipino na may Ingles at Bikol.

Sa pagsusuri mapapansin na ang mga mag-aaral sa teknolohiya at accountancy, enhinyero at arkitektura ay Filipino na may Ingles ang uri ng pasalitang Filipino na may 25 o 50 bahagdan at 24 o 48 na bahagdan ayon sa 
pagkakasunud-sunod samantalang ang mga mag-aaral sa kolehiyo ng edukasyon ay standard na Filipino ang uri ng pasalitang Filipino na may 20 o 40 bahagdan.

Sa pag-aaral na ito, natuklasan na ang pasalitang Filipino ng mga mag-aaral sa antas kolehiyo ng SSc ang nakararami ay Filipino na may Ingles at Bikol. Ito’y pinatunayan ng naging resulta ng pag-aaral ni Escobedo na kung saan inalam niya ang antas ng pasalitang Filipino ng mga mag-aaral sa sekundarya partikular ang Baitang 10. Napag-alaman niya na ang linggwistikong pagsusuri sa ponolohiya, bokabularyo at sintaksis ng pasaitang Filipino ng mga mag-aaral ay Filipino na may Ingles. Ito ay nagpapakita lamang na hindi maiiwasan ng mga mag-aaral ang paggamit ng Ingles sa kanilang pasalitang Filipino. Nagpapakita pa rin ito ng impluwensya ng Ingles sa kanilang pangalawang wika.

Ito ay nagpapatotoo rin na ang isang wikang buhay katulad ng Filipino ay umuulad sa paggamit at paghiram ng mga salita sa iba't ibang dayuhang wika ay proseso ng intelektwalisasyon at paghiram ng mga salita sa ibang katutubong wika ng Pilipinas na ayon kay Pineda ay proseso ng leksikulturalisasyon. Sinang-ayunan din ito ni Constantino (banggit ni Pineda et al., 1987) na ayon sa kanyan ang wika ay iba-iba ang varayti. Sa pagkakaibang ito nagbunga ng iba't ibang pagtingin, pananaw, at atityud kaugnay a hindi pagkakapantay pantay ng mga wika pati ng mga tagapagsalita, kultura, at sibilisasyon.

\subsection{Uri ng ponolohiya ng pasalitang Filipino ng mga mag-aaral sa antas kolehiyo}

Ang pasalitang Filipino ng mga mag-aaral sa antas kolehiyo ayon sa ponolohiya ay sinuri ayon sa alternasyon ng ponemang segmental na /e/ - /i/ at /o/ - /u/. Ang ponolohiya ay tumutukoy sa pag-aaral ng set ng tunog na bumubuo ng mga salita sa isang wika.

\section{Talahanayan 2}

Uri ng ponolohiya ng pasalitang Filipino ng mga mag-aaral sa antas kolehiyo

\begin{tabular}{|c|c|c|c|c|c|c|c|c|c|}
\hline Kolehiyo & $\begin{array}{c}\text { Wastong } \\
\text { bigkas }\end{array}$ & $\%$ & $\begin{array}{l}\text { Filipino na } \\
\text { may Ingles }\end{array}$ & $\%$ & $\begin{array}{c}\text { Karamiha' } \\
\text { y maling } \\
\text { bigkas }\end{array}$ & $\%$ & $\begin{array}{c}\text { Malin } \\
\text { g } \\
\text { bigkas }\end{array}$ & $\%$ & $\begin{array}{c}\text { Kabuuang } \\
\text { bilang ng mga } \\
\text { mag-aaral }\end{array}$ \\
\hline Edukasyon & 35 & 70 & 15 & 30 & - & - & - & - & 50 \\
\hline Teknolohiya & 32 & 64 & 18 & 36 & - & - & - & - & 50 \\
\hline Enhinyero at Arkitektura & 32 & 64 & 18 & 36 & - & - & - & - & 50 \\
\hline Accountancy & 37 & 74 & 13 & 26 & - & - & - & - & 50 \\
\hline Kabuuan & 136 & 68 & 64 & 32 & & & & & 200 \\
\hline Ranggo & 1 & & 2 & & & & & & \\
\hline
\end{tabular}

Makikita sa Talahanayan 2 na ang uri ng ponolohiya ng pasalitang Filipino ng mga mag-aaral sa antas kolehiyo nakararami 136 o 68 bahagdan ay may wastong bigkas at 64 o 32 bahagdan ang may kaunting maling bigkas samantalang walang karamiha'y may maling bigkas at maling bigkas.

Ipinapakita sa pagsusuring ito na ang nakararami 37 o 74 bahagdan sa mga mag-aaral sa kolehiyo ng accountancy na wasto ang bigkas ng ponemang segmental na /e/ - /i/ at /o/ - /u/ sa mga salitang ginamit kasunod ang edukasyon na may 35 o 70 bahagdan ang wastong bigkas, samantalang ang teknolohiya at enhinyero at arkitektura ay magkatulad na 32 o 64 na bahagdan ang may wastong bigkas. Kaunti, 13 o 26 na bahagdan sa mag-aaral sa accountancy ang may kaunting maling bigkas. Ang mga mag-aaral sa teknolohiya at enhinyero at arkitektura ay may magkatulad na 18 o 36 na bahagdan na may kaunting maling bigkas samantalang ang mag-aaral sa edukasyon ay may 15 o 30 bahagdan ang may maling bigkas.

Nabatid sa pag-aaral na ang nakararami sa mga mag-aaral ay wasto ang bigkas ng mga salitang may ponemang segmenta na /e/ - / i/ at /o/ - /u/ sa kanilang pasalitang Filipino. Bagama't lumabas sa resulta ng pag-aaral na mas nakararami ang wasto ang pagkakabigkas ng mga salita, may mga mag-aaral na natukoy na may kaunting maling bigkas din ito ng mga salita. Ang kalagayang ito ay nangangailangan pa rin ng pansin. Ito ay nagbibigay sa atin ng eksaktong larawan sa kalagayan ng pag-unlad ng pasalitang Filipino. 
Mapapansin rin na sa resulta ng pagkakaroon ng maling bigkas sa pagsasalita ng mga mag-aaral ay sa kadahilanang paggamit ng pinaghalong Filipino at Ingles at Filipino at Bikol. Pinatunayan na sa paggamit ng ibang wika, hindi maiiwasan ang magkaroon ng pagkakamali o linggwistikong intereferns sa tono. Sinang-ayunan din ito ng naging resulta ng pag-aaral ni Malana na ang kakulangan ng kaalaman ng mag-aaral sa linggwistikong Filipino at mga dahilan sa maling pagbigkas. Ipinapakita din dito ang epekto nito sa pagkatuto ng mga mag-aaral sa kanilang mga araling tinatalakay.

Ang mga suliraning kinakaharap ng mga Kalinga sa pagsasalita ng Wikang Filipino. Natuklasan na ang mga suliranin ay ang pagpapalit ng ilang mga tunog na wala sa Kalinga na nagagamit sa wikang Filipino at ang pagdala ng intonasyon, diin, at tono sa kanilang unang wika sa pagsasalita ng Filipino. Ang natuklasang ito sa nasabing pag-aaral ay nakita rin sa kasalukuyang pag-aaral. Mapapansin na ang ilang mga salita pagbinigkas ng mga mag-aaral ay nababago ang diin at tono na lumilikha ng pagbabago ng kahulugan ng salita. Epekto ito ng kung ano ang kanilang diyalekto (Taez, 2012).

\subsection{Uri ng leksikon sa pasalitang Filipino ng mga mag-aaral}

Ang leksikon ay tumutukoy sa mga salitang pambansa, pampanitikan, lalawiganin, balbal at kolokyal na ginamit ng mga kalahok sa pag-aaral. Ang pasalitang Filipino ng mga mag-aaral ay sinuri ayon sa kung ito ay panghihiram, pag-imbento ng mga salita, paraphrasing, at inkorporasyon. Panghihiram kapag mula sa mga wikang banyaga at katutubong salita, hiniram ay maaaring sa orihinal na anyo o naiiba, pag-imbento ng salita kung pagbubuo ng likhang salita na hindi naayon sa isinasaad ng batas, paraphrasing kung pagpapaliwanag sa nais sabihin sa pamamagitan ng halimbawa, depinisyon, pagsasalin, deskripsyon at sinonim at inkorporasyon paggamit ng mga salita sa iba’t ibang wika ng Pilipinas na kinikilala ng konstitusyon bilang batayan ng Filipino.

\section{Talahanayan 3A}

Uri ng leksikon sa pasalitang Filipino ng mga mag-aaral sa antas kolehiyo

\begin{tabular}{|c|c|c|c|c|c|c|c|c|c|}
\hline Kolehiyo & $\begin{array}{l}\text { Pang- } \\
\text { hihiram }\end{array}$ & $\%$ & $\begin{array}{l}\text { Pag-imbento } \\
\text { ng mga salita }\end{array}$ & $\%$ & $\begin{array}{c}\text { Para- } \\
\text { Phrasing }\end{array}$ & $\%$ & $\begin{array}{c}\text { Inkor- } \\
\text { porasyon }\end{array}$ & $\%$ & $\begin{array}{c}\text { Kabuuang } \\
\text { bilang ng mga } \\
\text { mag-aaral }\end{array}$ \\
\hline Edukasyon & 20 & 40 & - & - & 30 & 60 & - & - & 50 \\
\hline Teknolohiya & 22 & 44 & - & - & 28 & 56 & - & - & 50 \\
\hline Enhinyero at Arkitektura & 20 & 40 & - & - & 30 & 60 & - & - & 50 \\
\hline Accountancy & 26 & 52 & - & - & 24 & 48 & - & - & 50 \\
\hline Kabuuan & 88 & 44 & & & 112 & 56 & & & 200 \\
\hline Ranggo & & 2 & & & & 1 & & & \\
\hline
\end{tabular}

Inilahad sa Talahanayan 3 na nakararami 112 o 56 na bahagdan ang leksikon ay paraphrasing at 88 o 44 na bahagdan ang panghihiram. Samantalang wala sa mga mag-aaral na kalahok sa pag-aaral na ang leksikon ay pag-iimbento ng mga bagong salita at inkorporasyon.

Natuklasan sa pagsusuring ito na magkatulad ang mga mag-aaral sa edukasyon at enhinyero at arkitektura na 30 o 60 bahagdan ang leksikon na paraphrasing samantalang 28 o 56 at 24 o 48 na paraphrasing ang teknolohiya at accountancy.

Makikita na sa pasalitang Filipino ng mga mag-aaral sa kolehiyo, sila ay may kadahupan sa talasalitang Filipino o hindi pa gaanong malawak at mayaman ang kanilang talasalitaang Filipino. Ito ay totoo sapagkat sa halip na gumamit ng angkop na salitang Filipino sila ay nagpapaliwanag o paraphrasing. Sinabi nga ni Delima na madalas na ang lumalabas sa pagsasalita ng tao ay pagpapaliwanag sa nais sabihin sa pamamagitan ng halimbawa, depinisyon, pagsasalin, deskripsyon at sinonim sa halip na magbigay lamang ng angkop na salita.

Sinabi ni Corson (banggit ni Malana, 2013) na sa anumang lebel ng pag-aaral lubos na kailangan ng isang mag-aaral ang pagtataglay ng kasanayang linggwistik, lalo na ang pagkakaroon ng malawak na bokabularyo, sa pag-unawa at pagtalakay ng paksang pinag-aaralan. Magkakaroon naman ng kasanayan sa pagsasalita sa pamamagitan ng pakikinig. Ang pakikinig ay mahalaga upang matutong magsalita. Sa pakikinig natutuhan nang 
malaki ang wika kung paano gamitin at kung ano ang kahulugan nito.

Ang ilang halimbawa ng kanilang paraphrasing ay:

"Nakikita ko sa kanila kung paano nagkakabuklod-buklod hindi gaya halimbawa hindi sila katulad ng user of friend, totoo sila kung makisalamuha at umaayon sa kanila kung kailangan."

"Tulad po halimbawa sa palabas na ang mga guest ay iyong graduate ng PMa na babae. Nalaman kop o doon ang buhay-buhay ng isang babaeng sundalo.”

"Istorya ng dalawang tin-edyer nan a magkaiba ang personalidad, Bale c Kim ay isang socialites samantalang si Celine ay isang promdi.”

Natuklasan din sa leksikon sa pasalitang Filipino na ang mga mag-aaral ay nanghihiram ng mga salitang Ingles at maging salitang Bikol. Mapapansin na ang panghihiram na nakita ay ang mga sumusunod: panghihiram ng salita Ingles na kinuha sa katumbas sa Kastila at pagbaybay dito nang ayon sa palabaybayang Filipino, paghiram sa salitang Ingles at pagbaybay dito ayon sa palabaybayang Filipino at panghihiram sa salitang Ingles o dayuhan na walang pagbabago sa baybay. Ang panghihiram ng mga mag-aaral sa kanilang pasalitang Filipino ay ang panghihiram na panloob at panlabas, bagamat nakahihigit ang panghiram na panlabas sa mga salitang Ingles, gayundin ang panghihiram ng mga salitang Bikol. Na ayon nga kay dalawa ang uri ng panghihiram, ang panlabas at panloob. Ang panloob na panghihiram kung ang mga salita ay mula sa iba't ibang katutubong wika ng isang bansa samantalang ang panlabas ay paghiram ng mga salita sa ibang bansa o salitang dayuhan.

Nangangahulugan kung gayon na nangangailangan ng pagsasanay ang mga mag-aaral sa pagsasalita gamit ang wikang Filipino. Dapat na mabigyang ng tamang mga gawain na higit na lilinang sa talasalitaan upang maayos na magamit ito sa pakikipagtalastasan. Ayon nga kay Escobedo (2015) na sa aktwal na pagsasalita ang kaalaman at kahandaan ay dapat ipakita. Ang mga salita ay mabisang kasangkapan sa komunikasyon. Subalit upang maisakatuparan ng mga salita ang isang ispesipikong layunin kailangang maingat na piliin ang mga ito. Ibig sabihin, hindi basta-basta ang paggamit ng salita, alam dapat ng nagsasalita ang kahulugan nito.

\subsection{Uri ng sintaks ayon sa haba sa pasalitang Filipino ng mga mag-aaral}

Ang sintaks ay ang masistemang pagsasama-sama o pag-uugnay ng mga salita sa pangungusap. Tinukoy ang haba sa kung ano ang sukat ng bilang ng mga salita. Ang pasalitang Filipino ng mga mag-aaral ayon sa sintaks ay sinuri sa katamtamang paggamit ng maikli at mahabang pangungusap, maraming paggamit ng katamtamang haba ng pangungusap, katamtamang paggamit ng paungusap na may isa hanggang apat na sugnay, maramihang paggamit ng pangungusao na may dalwa hanggang tatlong sugnay at madalang na paggamit ng pangungusap na may lima o mas maraming sugnay.

\section{Talahanayan 3B.1}

Uri ng sintaks sa haba sa pasalitang Filipino ng mga mag-aaral sa antas kolehiyo

\begin{tabular}{lccccccccccc}
\hline \multicolumn{1}{c}{ Kolehiyo } & 1 & $\%$ & 2 & $\%$ & 3 & $\%$ & 4 & $\%$ & 5 & $\%$ & $\begin{array}{c}\text { Kabuuang bilang } \\
\text { ng mga mag-aaral }\end{array}$ \\
\hline Edukasyon & 25 & 50 & 23 & 46 & 2 & 4 & - & - & & 50 \\
Teknolohiya & 27 & 54 & 22 & 44 & 1 & 2 & - & - & & 50 \\
Enhinyero at Arkitektura & 22 & 44 & 26 & 52 & 2 & 4 & - & - & & 50 \\
Accountancy & 24 & 48 & 24 & 48 & 2 & 4 & - & - & & 50 \\
& Kabuuan & 98 & 49 & 95 & 47.5 & 7 & 3.5 & & & & 200 \\
& Ranggo & & 1 & & 2 & & 3 & & & \\
\hline
\end{tabular}

1. Katamatamang paggamit ng maikli at mahabang pangungusap

2. Maramihang paggamit ng katamtamang haba ng pangungusap

3. Katamtamang paggamit ng pangungusap na may isa hanggang apat na sugnay

4. Maramihang paggamit ng pangungusap na may dalawa hanggang tatlong sugnay

5. Madalang na paggamit ng pangungusap na may lima o mas maraming sugnay 
Sa ginawang ebalwasyon sa Talahanayan 3B.1 sa uri ng sintaks ayon sa haba sa pasalitang Filipino, natuklasan na 98 o 49 bahaagdan ang may katamtamang paggamit ng maikli at mahabang pangungusap, 95 o 47.5 na bahagdan ang maramihang paggamit ng katamtamang haba ng pangungusap at 7 o 3.5 na bahagdan ang katamtamang paggamit ng pangungusap na may isa hanggang apat na sugnay. Samantalang walang maramihang paggamit ng pangungusap na may dalawa hanggang tatlong sugnay.

Mapapansin na ang mga mag-aaral sa departamento ng teknolohiya, ang nakararami 27 o 54 na bahagdan ay may katamtamang paggamit ng maikli at mahabang pangungusap. Sinusundan ito ng edukasyon, accountancy, at enhinyero at arkitektura na may 25 o 50, 24 o 48 at 22 o 44 ayon sa pagkakasunud-sunod. Ang mag-aaral sa departamento ng enhinyero at arkitektura ang karamihan 26 o 52 bahagdan ang may maramihang paggamit ng katamtamang haba ng pangungusap. Sinundan ito accountancy na may 24 o 48 na bahagdan, edukasyon 23 o 46 at teknolohiya na may 22 o 44 na bahagdan ang katamtaman ang haba ng pangungusap. Ang mga mag-aaral sa edukasyon, enhinyero at arkitektura, at accountancy ay may 2 o 4 na bahagdan ang may katamtamang paggamit ng pangungusap na may isa hanggang apat na sugnay samantala 1 o 2 bahagdan ang teknolohiya.

Nabatid sa pag-aaral na ang nakararami sa uri ng sintaks ayon sa haba sa pasalitang Filipino ng mga mag-aaral ay ang katamtamang paggamit ng maikli at mahabang pangungusap. Ito ay nagpapakita na sila ay may kakayahang magpahayag ng kanilang kaisipan at damdamin sa wikang Filipino sa maaikli at mahabang pangungusap. Ito ay nagpapakita pa rin sa pangkalahatan na sila ay may kakayahan sa pagpapahayag kung ang sariling wika ang ginagamit. Alam natin na walang mataas, mahirap o abstraktong kaisipan na hindi maaaring ihayag sa sariling wika. Alam din natin na kapan ang isang tao ay napipilitan sa pagsasalita sa isang wikang dayuhan na bagama't naiintindihan niya'y hindi naman niya nasasalita, lalabas itong mangmang at walang nalalaman. Subalit kapag ibinalik mo sa karaniwang mamamayan ang kanyang sariling wika, kahit pa sinong diputadong tao handa siyang makipagtalo.

\subsection{Uri ng sintaks ayon sa codeswitching sa pasalitang Filipino ng mga mag-aaral}

Ang codeswitching ay ang paggamit ng ibang wika, partial o lubusan habang gumagamit ng isang wika. Ang pasalitang Filipino ng mga mag-aaral ayon sa codeswitching ay sinuri ayon sa kung ito ay partial at lubusan.

\section{Talahanayan 3B.2}

Uring sintaks ayon sa codeswitching sa pasalitang Filipino ng mga mag-aaral sa antas kolehiyo

\begin{tabular}{|c|c|c|c|c|c|c|c|}
\hline Kolehiyo & Partial & $\%$ & Lubusan & $\%$ & $\begin{array}{c}\text { Walang } \\
\text { Code-switching }\end{array}$ & $\%$ & $\begin{array}{c}\text { Kabuuang bilang ng } \\
\text { mga mag-aaral }\end{array}$ \\
\hline Edukasyon & 28 & 56 & - & - & 22 & 44 & 50 \\
\hline Teknolohiya & 26 & 52 & - & - & 24 & 48 & 50 \\
\hline Enhinyero at Arkitektura & 30 & 60 & - & - & 20 & 40 & 50 \\
\hline Accountancy & 29 & 58 & - & - & 21 & 42 & 50 \\
\hline Kabuuan & 113 & 56.5 & & & 87 & 43.5 & 200 \\
\hline Ranggo & & 1 & & & & 2 & \\
\hline
\end{tabular}

Makikita sa Talahanayan 3B.2 sa uri ng sintaks ayonsa codeswitching sa pasalitang Filipino na 113 o 56.5 na bahagdan ang codeswitching ng mga mag-aaral ay partial at walang codeswitching na lubsan. Samantalang $87 \mathrm{o}$ 43.5 na bahagdan ay hindi nag-codeswitching.

Mapapansin na ang enhinyero at arkitektura ay 30 o 60 bahagdan ang may partial na codeswitching, samantalang 29 o 58 na bahagdan, 28 o 56 na bahagdan at 26 o 52 na bahagdan ang partial na codeswitching ng accountancy, edukasyon at teknolohiya ayon sa pagkakasunud-sunod. Walang codeswitching ang mga mag-aaral sa teknolohiya na may 24 o 48 bahagdan samantalang 22 o 44 na bahagdan, 21 o 42 bahagdan, at 20 o 40 bahagdan ang walang codeswitching sa edukasyon, accountancy, at enhinyero at arkitektura ayon sa pagkakasunud-sunod.

Sa pagsusuring ginawa natuklasan na ang nakararami sa mga mag-aaral ay may codeswitching sa kanilang

16 Consortia Academia Publishing (A partner of Network of Professional Researchers and Educators) 
pasalitang Filipino bagaman ito ay partial lamang. Sa natuklasang datos sa uri ng leksikon sa pasalitang Filipino, nagparaphrasing ang mga mag-aaral dahil sa kakulangan sa talasalitaang Filipino o hindi pa gaanong mayaman at malawak ang kanilang talasalitaan Filipino kaugnay nito kung kaya't ang mga mag-aaral ay nagkakaroon ng codeswitching sa sintaks sa kanilang pasalitang Filipino. Ang pagkakaroon ng codeswitching ng mga mag-aaral sa kanilang pagsasalita ay impluwensya ng kung ano ang kanilang nasa kapaligiran, nariyan din ang pagsunod sa uso, pagbibigay-linaw o dahil sa wala nang maitumbas sa wikang Filipino. Ang mga Pilipino ay kusang nagagamit ang code switching sa pagitan ng Ingles at katutubong wika kung saan komportable sa pagbibigay ng mensahe. Binanggit din niya na likas na lilitaw sa isang tao sa kanyang pagsasalita ang unang wika. Dahil sa codeswitching na nagaganap nakakakuha ng atensyon at ito rin ay nagpapalakas ng motibasyon sa masusing pag-intindi ng mga mensaheng inilalahad (Maga, 2010).

Narito ang ilang halimbawa ng mga pangungusap na naganap ang partial at lubusang codeswitching:

"Actualy po maganda ang palabas na Probinsiyano kasi maraming nakakarelate na tao sa mensahe ng kuwento."

"Ako po pa'no bihirang makapanood ng mga palabas kasi po tumutulong muna ako sa kapatid gumawa ng mga decorations para sa Christmas tree."

"I admire him for being so guwapo."

"Now more than ever you need to support him by reminding him na mali ang ginagawa niya."

Sa naging resulta ng pag-aaral masasabing magkatulad ang nagaganap sa pagamit ng code switching ang mga mag-aaral sa pakikibahagi sa talakayan sa iba't ibang asignatura. Tinukoy din dito ang naging epekto nito sa pagkatuto sa mga konsepto nagaganap sa bawat asignatura at ang pagkabihasa sa wika. Sa pangangalap niya ng mga datos, gumamit din ng metodolohiya ng pagrerekord. Sinuportahan ito ng pag-aaral ni Bautista (2004) ang Tagalog-English code-switching o ang pagpapalit sa paggamit ng wikang Ingles sa wikang Filipino, ay nakapalibot sa atin. Ito ay isang obserbasyon ng mga dayuhan na bumibisita sa Pilipinas, lalong lalo na sa Maynila.

\section{Konklusyon at rekomendasyon}

Batay sa natuklasan sa pasalitang Filipino ng mga mag-aaral sa antas kolehiyo, nabuo ang mga sumusunod: Hindi pa standard ang uri ng pasalitang Filipino ng mga mag-aaral kundi Filipino na may Ingles ang uri ng pasalitang Filipino. Wasto at di nagkakapalitan ang bigkas ng mga mag-aaral sa ponemang segmental na /e/ - /i/ at /o/ - /u/. Paraphrasing ang uri ng leksikon ng mga mag-aaral sa kanilang pasalitang Filipino. Katamtaman ang paggamit ng maikli at mahabang pangungusap sa sintaks ayon sa haba sa pasalitang Filipino ng mga mag-aaral. Partial ang kanilang codeswitching sa pasalitang Filipino.

Inirerekomenda ang sumusunod: Bigyan ng higit na maraming pasalitang praktikum ang mga mag-aaral na hindi gaanong nalinang ang kasanayan sa wikang Filipino tungo sa higit na pagkalinang sa kanilang sariling wika. Ang lahat ng guro sa/ng Filipino ay bigyan ng pagkakataong dumalo sa mga seminar-worksyap sa Filipino upang higit na mapaunlad ang kakayahan sa pasalitang Filipino. Gumamit ang mga guro ng iba't ibang estratehiya sa paglinang ng kakayahan ng mga mag-aaral sa pagsasalita. Magsagawa ng iba pang pag-aaral sa pasalitang Filipino sa iba't ibang panig ng Pilipinas na magiging batayan sa proseso ng istandardisasyon ng Filipino. Magbigay ng insentibo sa mga mag-aaral na huwaran ang pasalitang Filipino sa pagbibigay ng mataas na marka at iskolarsyip. Maging modelo ang mga guro sa kanilang mag-aaral sa pagsalita ng standard na Filipino. Parangalan at mga guro at mag-aaral na huwaran ang pasalitang Filipino sa pagdiriwang ng Buwan ng Wika. 


\section{Sanggunian}

Almario, V. S. (2015). KWF manwal sa masinop na pagsulat ( ${ }^{\text {nd }}$ ed.). Komisyon ng Wikang Filipino.

Bautista, M. L. S. (2013). Tagalog-English code-switching as a mode of discourse. Asia Pacific Education Review, 5(2), 226-233. https://doi.org/10.1007/BF03024960

Bernales, R. A., et al. (2016). Komunikasyon at pananaliksik sa wika at kulturang Pilipino. Malabon: Mutya Publishing House.

Boydon, S. (2014). Wikang Filipino, sagisag ng pagkapilipino. Philippines.

Delima, P. G. (1996). Umuusbong na varyti ng Filipino bilang interlanguage ng mga katutubo at di katutubong ispiker na Tagalog. Daluyan. Journal ng SWF sa Talakayang Pangwika, 7(3).

Escobedo, A. F. (2015). Antas ng pasalitang Filipino ng mga mag-aaral sa baitang 10. Philippines.

Jamisola, R. L. (2020). Linggwiatikong pag-aral sa pagpapalit koda sa mass media [Di-Limbag na Disertasyon]. Paaralang Gradwado, Sorsogon State College, Sorsogon City.

Jolo, M. J. D. (2020). Millenial slang sa pakikipagtalastasang Filipino [Di-Limbag na Tesis]. Paaralang Gradwado, Sorsogon State College, Sorsogon City.

Kautusang Pangkagawaran Blg 52, s. 1987.

Konstitusyon ng 1987, Atas Tagaganap Blg. 335.

Maga, A. A. (2010). Codeswitching factors among students: Basi in the development of teaching strategies for communicative competence [Unpublished Thesis]. Graduate School, Sorsogon State College, Sorsogon City.

Malana, C. J., et al. (2013). Mga suliranin sa pagtuturo ng pagbabaybay sa wikang Filipino sa sekondaryang paaralan [Di-limbag na tesis].

Ojos, M. K. H. (2020). Kaalaman ng seniors high school sa sulating pananaliksik sa mataas na paaralan sa lalawigan ng Sorsogon [Di-Limbag na Tesis]. Paaralang Gradwado, Sorsogon State College, Sorsogon City.

Pineda, P. B. P., et al. (1987). Sining ng komunikasyon. Katha Publishing.

Santiago, A., at Tiangco, N. (2003). Makabagong balarilang Filipino. Manila: Rex Bookstore.

Taez, J. T. (2012). Suliraning kinakaharap ng mga kalinga sa pagsasalita ng wikang Filipino. Isang pananaliksik na iniharap sa paaralang di-gradwado ng paaralan ng edukasyong pangguro ng San Luis, lungsod ng Baguio.

Yule, G. (2014). The study of language. UK: Cambridge University Press. 